With regard to pragmatic opinions which rate scientific researches in terms of their effects, incomplete and even earlier studies of little understood but important phenomena may have more farreaching and beneficial effects than studies of higher quality that deal either with inconsequential matters or with matters already well understood in their essentials. Great works of complation may be rated very high from the pragmatic point of view, because of the many practical purposes they serve and the stimulus they furnish for the development of scientific theories. Pragmatic opinions also largely fashion the response of the scientific worker to group motives, and here Dr. Wright stresses obstacles which antiscientific practices arising from such motives offer to the advancement of science. Three types are indicated : the wilful distortion of truth to mislead rival groups; suppression of the results of scientific research to prevent rivals benefiting by them; and use, as in war, of the results of scientific research to injure rival groups. Ethics and science, he holds, are inextricably linked, and unethical practices are not only anti-social but also anti-scientific. Again, he urges that the advancement of science demands the continuous discovery of new truths and the continuous development of new hypotheses, for which the fullest and freest possible interchange of knowledge is prerequisite. Dealing briefly in conclusion with the effects of war on science and with the reconstruction of scientific endeavour after the War, Dr. Wright admits that war may lead to rapid advances along certain specific lines of research, but suggests that the transition problems may be even more difficult than those in waging war itself. $\mathrm{H}_{\Theta}$ urges concentrated effort to forestall the loss or destruction of the masses of information accumulated for war-time purposes.

\section{Incentives in Industry}

IN an address to the Leicester Centre of the Institute of Industrial Administration on "Incentives for Indirect Workers" ( $J$. Inst. Indust. Admin., 5, 14 ; 1944), Mr. Harold White gives an interesting analysis of the incentives affecting workers not directly engaged in manufacturing processes or the assembly or finishing of products. After discussing the characteristic features of the indirect worker's job, he indicates seven types of incentive-particular interest in the type of work, personal pride in the apparent importance of the position held, increase in rate of pay, opportunities for promotion, bonuses based on earnings of direct workers, ex gratia bonuses, and permanency of position-the effectiveness of which depends largely on the intelligence and ambition of the individual and the general nature of his job. Factors on which actual bonus schemes have been based are next considered, and Mr. Whitehead's review of these schemes leads him to six conclusions, as follow. The big majority had proved sufficiently satisfactory to be considered a permanent feature of the company's policy. The more direct the bonus to the indirect worker, the better the response. Confidence in the management is essential to the success of a scheme. 'Ready-made' schemes are dangerous ; no standard programme of incentives can be laid down for adoption without studying and evaluating internal circumstances. An incentive plan for indirect workers cannot be established by intuition: it demands thorough and careful forethought. The probable results, in cash, to the indirect workers must be fully considered, so that the probable amount is a real incentive, and not merely a financial liability to the company.

\section{Science in Post-Primary Education}

AN interim report has recently been compiled by the Association of Women Science Teachers with the view of submitting a scheme for the teaching of science in the post-primary schools of the future (An Interim Report of a Sub-Committee of the Association of Women Science Teachers. Pp. vi+22. London: John Murray, 1944. 1s. 3d. net). The subcommittee which submitted this report considers the needs of all types of children within the secondary school range, dealing fully with the ideals that should permeate the science teaching and with the need for a change of outlook. Although the present publication outlines full syllabuses for children of eleven to sixteen years only, a subsequent publication, already in preparation, will also contain chapters on sixth form science, part-time education in science, the training of teachers and administrative problems. A useful chapter on laboratories and equipment, the museum, first aid, organization of department and other matters will be appended.

The five-year course of general science suggested is based on the fundamental principles of social relationships; selection from the syllabuses, by the teacher, will be necessary, as these syllabuses are thought to contain the maximum for children of the highest intelligence, given the best opportunity. For the first two years, the topics considered are the universe and its attributes of light, heat and gravitation,.water, air, land and people; for the last three years those of energy, matter and life. Methods of presentation are discussed and time allowances for science recommended. A progressive outlook has produced syllabuses that are less academic than usual, although the experimental and objective attitude to problems is regarded throughout as of paramount importance.

\section{Royal Institution}

Dr. L. R. G. Treloar delivered a discourse at the Royal Institution on December 15, speaking on "Rubbers and their Characteristics: Real and Ideal". He pointed out that although rubbers are diverse in chemical constitution, they all conform to a general type of molecular structure, and it is in this structure that the origin of the remarkable physical properties of rubbers is to be found. All rubbers are built up of enormously long chain-like molecules which are linked together so as to form a loose three-dimensional network. The atoms of the molecular chain are in a state of continuous motion, due to their thermal energy; hence the molecule tends to take up a randomly-kinked, continuously fluctuating form, in which its effective length is only a small fraction of the full chain-length. As a result, the molecule exhibits elasticity. The elasticity of rubbers, like that of gases, is thus kinetic in origin. Rubber-like elasticity is always limited to a certain range of temperature, varying with the chemical constitution of the molecule. At low temperature, rubbers are transformed to a glass-hard condition, whereas at high temperatures they tend to lose strength and to approach the condition of a highly viscous liquid. In some rubbers, also, a crystalline state is possible. Crystallization develops slowly in 